\title{
Concentrations of $n-3$ and $n-6$ fatty acids in Dutch bovine milk fat and their contribution to human dietary intake
}

\author{
H. J. F. van Valenberg, ${ }^{\star 1}{ }^{1}$ K. A. Hettinga, ${ }^{*}$ J. Dijkstra, † H. Bovenhuis, $\ddagger$ and E. J. M. Feskens§ \\ *Dairy Science and Technology Group of PDQ, Wageningen University, PO Box 8129, 6700 EV Wageningen, the Netherlands \\ †Animal Nutrition Group, Wageningen University, PO Box 338, 6700 AH Wageningen, the Netherlands \\ $\ddagger$ Animal Breeding and Genomics Centre, Wageningen University, PO Box 338, $6700 \mathrm{AH}$ Wageningen, the Netherlands \\ §Division of Human Nutrition, Wageningen University, PO Box 8129, 6700 EV Wageningen, the Netherlands
}

\begin{abstract}
Weekly samples representative of Dutch milk were analyzed for concentrations of n- 3 and n- 6 fatty acids (FA). Concentrations of the n-3 FA $\alpha$-linolenic acid (ALA), eicosatetraenoic acid, eicosapentaenoic acid, and docosapentaenoic acid were $0.495 \pm 0.027,0.041$ $\pm 0.004,0.067 \pm 0.005$, and $0.086 \pm 0.008 \mathrm{~g}$ per $100 \mathrm{~g}$ of fat, respectively, whereas docosahexaenoic acid was absent or present in concentrations lower than $0.020 \mathrm{~g}$ per $100 \mathrm{~g}$ of fat. Concentrations of the $\mathrm{n}-6 \mathrm{FA}$ linoleic acid (LeA), $\gamma$-linoleic acid, dihomo- $\gamma$-linoleic acid, and arachidonic acid were $1.428 \pm 0.068,0.070 \pm 0.007$, $0.066 \pm 0.004$, and $0.089 \pm 0.004 \mathrm{~g}$ per $100 \mathrm{~g}$ of fat, respectively; adrenic acid was present in concentrations lower than $0.020 \mathrm{~g}$ per $100 \mathrm{~g}$ of fat, whereas docosapentaenoic acid was absent in all samples. The concentrations of ALA and LeA were significantly higher in spring and summer, compared with autumn and winter. The concentrations of all other ALA- and LeAderived n-3 and n-6 FA were not significantly different between seasons. The contribution of milk fat to the daily intake of eicosapentaenoic acid, docosapentaenoic acid and docosahexaenoic acid was calculated for human consumption levels in different countries. Milk fat contributed between 10.7 and $14.1 \%$ to the daily intake of eicosapentaenoic acid and between 23.5 and $34.2 \%$ to the intake of docosapentaenoic acid; whereas docosahexaenoic acid contribution was marginal. Arachidonic acid from milk fat contributed between 10.5 and $18.8 \%$ to the human intake of n- 6 FA.
\end{abstract}

Key words: n-3 fatty acid, n- 6 fatty acid, milk fat, dietary intake

\section{INTRODUCTION}

Bovine milk fat mainly consists $(\sim 98 \%)$ of triglycerides, which contain a large variety of different FA. More

Received October 23, 2012.

Accepted March 22, 2013.

${ }^{1}$ Corresponding author: Hein.vanValenberg@wur.nl than 400 different FA have been identified in bovine milk but most of the FA are present in relative low concentrations (Jensen, 2002). Only 12 to 14 FA are present in concentrations higher than $1 \%$ of the milk fat (Walstra et al., 2006; Heck et al., 2009). Two of the minor long-chain FA present in milk, $\alpha$-linolenic acid (ALA; 18:3n-3) and linoleic acid (LeA; 18:2n-6) cannot be synthesized by cows because mammals are missing the desaturases that are needed to introduce double bonds at the $\Delta 12$ and $\Delta 15$ positions of FA (Arterburn et al., 2006). Therefore, ALA and LeA must be obtained from plant materials in the diet (Ratnayake and Galli, 2009). Mammals convert ALA and LeA metabolically into 2 different series of very long chain n-3 and n- 6 FA by a single set of desaturases and elongases (Sprecher, 2002). These FA are classified into the $n-3$ and $n-6$ families based on the position of the first double bond from the methyl end group in the FA chain.

$\alpha$-Linolenic acid is the precursor of very long chain n-3 PUFA such as eicosapentaenoic acid (EPA; 20:5n3) and docosahexaenoic acid (DHA; 22:6n-3). Figure 1 shows the n-3 pathway (Sprecher, 2000); starting from ALA, the chain length increases and extra double bonds are inserted at the carboxyl end of the FA molecules by the action of elongases and desaturases, respectively. The n-6 FA linoleic acid is converted into arachidonic acid (ARA; 20:4n-6) and finally into docosapentaenoic acid (DPA n-6; 22:5n-6) by the same set of elongases and desaturases (Figure 1). The metabolic pathway for conversion of ALA into EPA by cows is supposed to be similar to the human pathway (Hagemeister et al., 1991). The genes FADS1 and FADS2, encoding for $\Delta^{5}$ and $\Delta^{6}$-desaturase, respectively, are expressed in the bovine mammary gland (Bionaz and Loor, 2008).

Dietary intake of $n-3$ and n- 6 FA determines in large part the composition of cell membranes (Burdge, 2006; Simopoulos, 2008). In addition, EPA and ARA are metabolized into a group of signaling molecules, which are collectively referred to as eicosanoids. These low-abundance metabolites, as well as DHA-derived docosanoids, have a broad range of biological activities (Ratnayake and Galli, 2009). Long-chain n-3 FA 


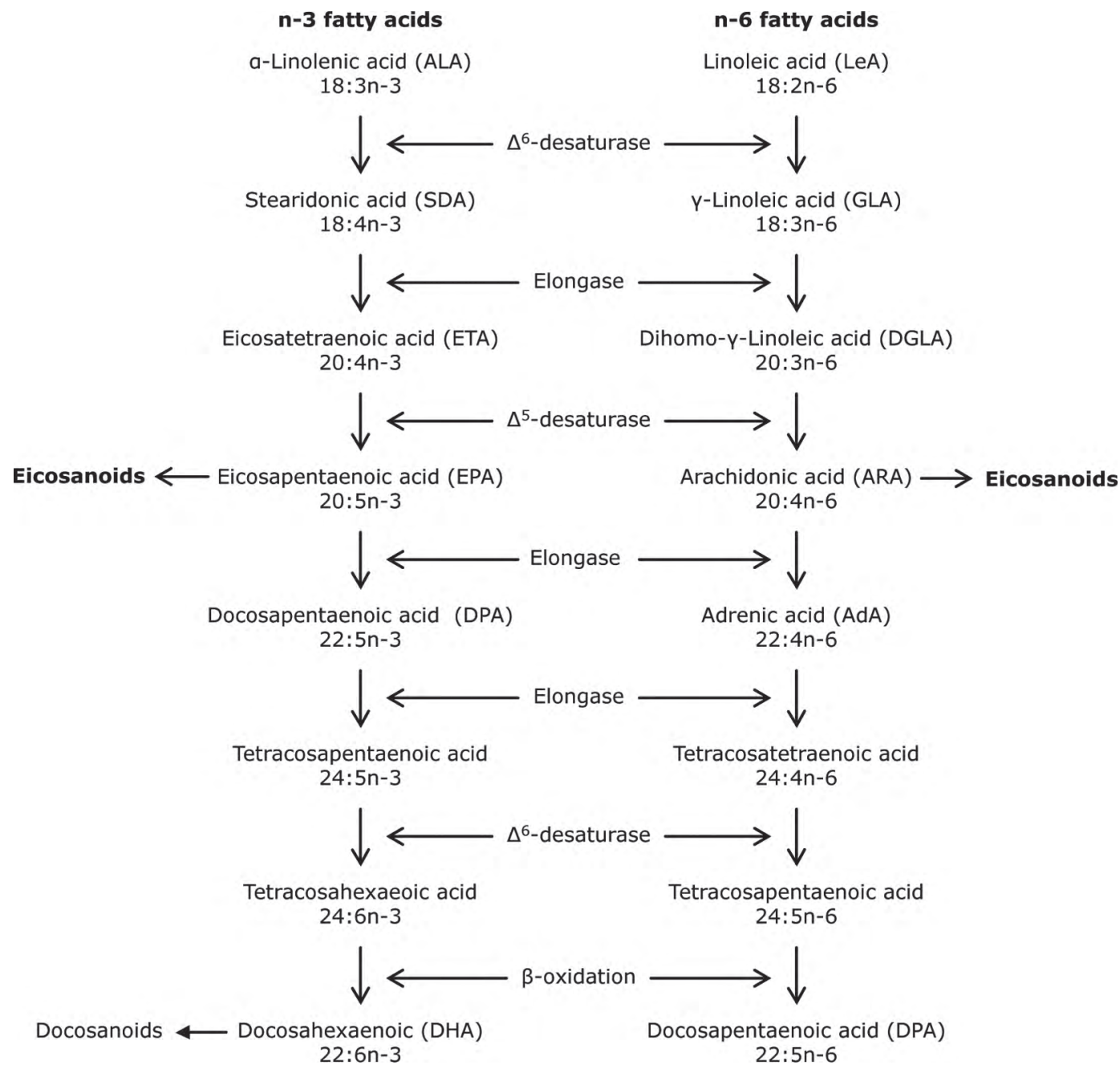

Figure 1. Metabolic pathways of n-3 and n-6 FA. Adapted with permission from Schmitz and Ecker (2008).

are substrates for production of less-inflammatory and, in some cases, antiinflammatory eicosanoids, whereas ARA is the precursor of proinflammatory and prothrombic eicosanoids (Calder, 2006).

Humans have the ability to metabolize ALA into EPA and DHA. The relative contribution of ALA for meeting the dietary demands of EPA and DHA is unknown (Bakewell et al., 2006) but this metabolic pathway does not provide adequate levels of EPA and DHA for optimal human health and nutrition (Anderson and Ma, 2009). To meet the recommend dietary intake, consumption of around $450 \mathrm{mg}$ of EPA + DHA per day is recommended in most countries, especially for prevention of coronary heart disease (Kris-Etherton et al., 2009).

The main source for EPA and DHA in human diets is fatty fish. In the absence of fatty fish consumption, the intake of n-3 FA is less than $100 \mathrm{mg} / \mathrm{d}$ (Calder, 2006), which is far below the recommended daily intake. Milk and dairy products are considered not to contribute significantly to dietary intake of n-3 FA (Astorg et al., 2004, Meyer et al., 2003; Sioen et al., 2006). However, in cow feeding trials, these FA are often reported to be present in milk from control diets but the low concentrations are considered as negligible for n-3 FA intake by humans (Lock and Bauman, 2004; Woods and Fearon, 2009; O'Donnell et al., 2010). Contrary to these results, a recent study suggested that milk fat may be a source for dietary intake of EPA, reporting that dairy products supply 10.7 to $11.3 \%$ of EPA in the diets of meat eaters and 18.4 to $26.3 \%$ of EPA in the diets of vegetarians (Welch et al., 2010).

In the present study, accurate concentrations of FA were obtained by analyses of composite samples that were representative of Dutch milk composition. These weekly samples also provide a reliable overview of the seasonal variation in milk fat composition (Heck et al., 2009). However, the study of Heck et al. (2009) did 
not report the variation in concentrations of very long chain $\mathrm{n}-3$ and n-6 FA. The objectives of the present study were to determine which FA belonging to the n-3 pathway or n-6 pathway can be identified and quantified in bovine milk fat to determine the variability of n-3 and n-6 FA throughout the year, and to calculate the contributions of EPA, DPA, DHA, and ARA to the dietary intake by humans.

\section{MATERIALS AND METHODS}

The samples used were bovine milk samples that are collected weekly by the Dutch milk control station (Qlip, Zutphen, the Netherlands) as a representative Dutch milk sample. Every week from March 2011 to February 2012, milk samples of $50 \mathrm{~L}$ each were collected from the bulk tanks (average size around 200,000 L) of 20 large dairy plants situated in different regions of the Netherlands. Samples were pooled and conserved with $0.03 \%$ sodium azide. Fifty-two subsamples of the pooled milk were stored at $4^{\circ} \mathrm{C}$ and analyzed for FA composition (samples of wk 22 and 23 have not been analyzed) within 1 wk after sample collection. The distribution of the weeks over the seasons is according to previous research (Heck et al., 2009): spring = wk 12 to 24 , summer $=$ wk 25 to 37 , autumn $=$ wk 38 to 50 , and winter $=$ wk 51 to 11 .

Milk fat was extracted from the pooled milk samples and FA methyl esters were prepared from the fat fractions as described in International Organization for Standardization (ISO) Standard 15884:2002 (ISO, 2002a). Methyl esters were analyzed according to ISO Standard 15885:2002 (ISO, 2002b) on a Trace GC Ultra chromatograph (Thermo Electron Corp., Madison, WI), using a Varian Fame Select column $(100 \mathrm{~m} \times$ 0.25-mm i.d.; Varian Inc., Palo Alto, CA). The initial temperature was held at $70^{\circ} \mathrm{C}$ for $1 \mathrm{~min}$, raised to $225^{\circ} \mathrm{C}$ at $3^{\circ} \mathrm{C} / \mathrm{min}$, and held at $225^{\circ} \mathrm{C}$ for $5 \mathrm{~min}$. A volume of 1 $\mu \mathrm{L}$ was injected. Each peak was identified and quantified using pure methyl ester standard (Sigma-Aldrich; Larodan). The FA were expressed as a proportion of total fat weight and expressed as grams per $100 \mathrm{~g}$ of fat. The FA containing $24 \mathrm{C}$ atoms could not be quantified because pure methyl esters of these FA are not available. Stearidonic acid (SDA; 18:4n-3) could not be identified because it co-eluted with trans-10,cis-11 C18:2.

Dietary intake of n-3 and n-6 PUFA provided by milk fat was calculated as follows:

$\mathrm{FA}(\%)=$

milk fat consumption $\times[\mathrm{FA}]$

milk fat consumption $\times[\mathrm{FA}]+$ intake of $\mathrm{FA}$ from other food sources
Milk fat consumption $(\mathrm{g} / \mathrm{d})$ and intake of each $\mathrm{n}-3$ and n-6 FA (g/d) from nondairy food sources were derived from the literature (Meyer et al., 2003; Astorg et al., 2004; Sioen et al., 2006), whereas concentrations of n-3 and $\mathrm{n}-6 \mathrm{FA}$ (g/100 g of fat) from milk fat were obtained from this study.

The n-3 and n-6 FA concentrations in different seasons were statistically evaluated by one-way ANOVA. Duncan's multiple range test was applied for detection of significant differences between mean FA concentrations.

\section{RESULTS AND DISCUSSION}

Average concentrations of ALA and LeA in milk fat were $0.495 \pm 0.068$ and $1.428 \pm 0.068 \mathrm{~g} / 100 \mathrm{~g}$ of fat (Table 1 ), which are within the ranges previously reported (Jensen, 2002). The LeA:ALA ratio of 2.88 falls within the recommended range, from $1: 1$ to $4: 1$, that is considered to be important for human homeostasis and normal development (Simopoulos, 2008). The concentrations of ALA and LeA throughout the year in the current study are close to those reported in the literature (Heck et al., 2009). In spring and summer, ALA and LeA concentrations were significantly higher than in autumn and winter. For cows, the main sources of ALA and LeA are grass and maize, respectively (Chilliard et al., 2001). In the outdoor season, grazing will increase the intake of ALA, whereas the intake of LeA from maize silage is lower compared with the indoor season (Chilliard et al., 2001; Heck et al., 2009). A large part of dietary ALA and LeA is biohydrogenated by rumen bacteria (Chilliard et al., 2007); ALA and LeA that escape rumen biohydrogenation will probably, as in other mammals, be $\beta$-oxidized (Cunnane et al., 2003), stored in body tissues, or incorporated in milk fat.

Linolenic acid and linoleic acid are metabolized to 2 distinct families of very long chain n- 3 and n- 6 FA. In contrast to ALA and LeA, concentrations of very long chain n-3 and n- 6 FA in bovine milk fat are not reported in review articles. For validation of our results, concentrations of very long chain n-3 and n- 6 FA were derived from control diets of cow feeding experiments in the past $10 \mathrm{yr}$. In general, control diets represent common diets without supplemental fat sources that may have affected milk fat content and composition. The number of cows in most of these trials was between 4 and 24, which implies a larger variability in results compared with our study. Literature values on concentrations of n-3 and n-6 FA in control diets of cows are summarized in Table 2 (n-3 FA) and in Table 3 (n-6 FA). Average concentrations of n-3 PUFA (Table 1) for Dutch milk fat are within the ranges obtained from the literature 
Table 1. Fat contents and concentrations (mean \pm SD) of $n$ PUFA ( $\mathrm{g} / 100 \mathrm{~g}$ of fat) in Dutch bovine raw milk during the different seasons of 2011

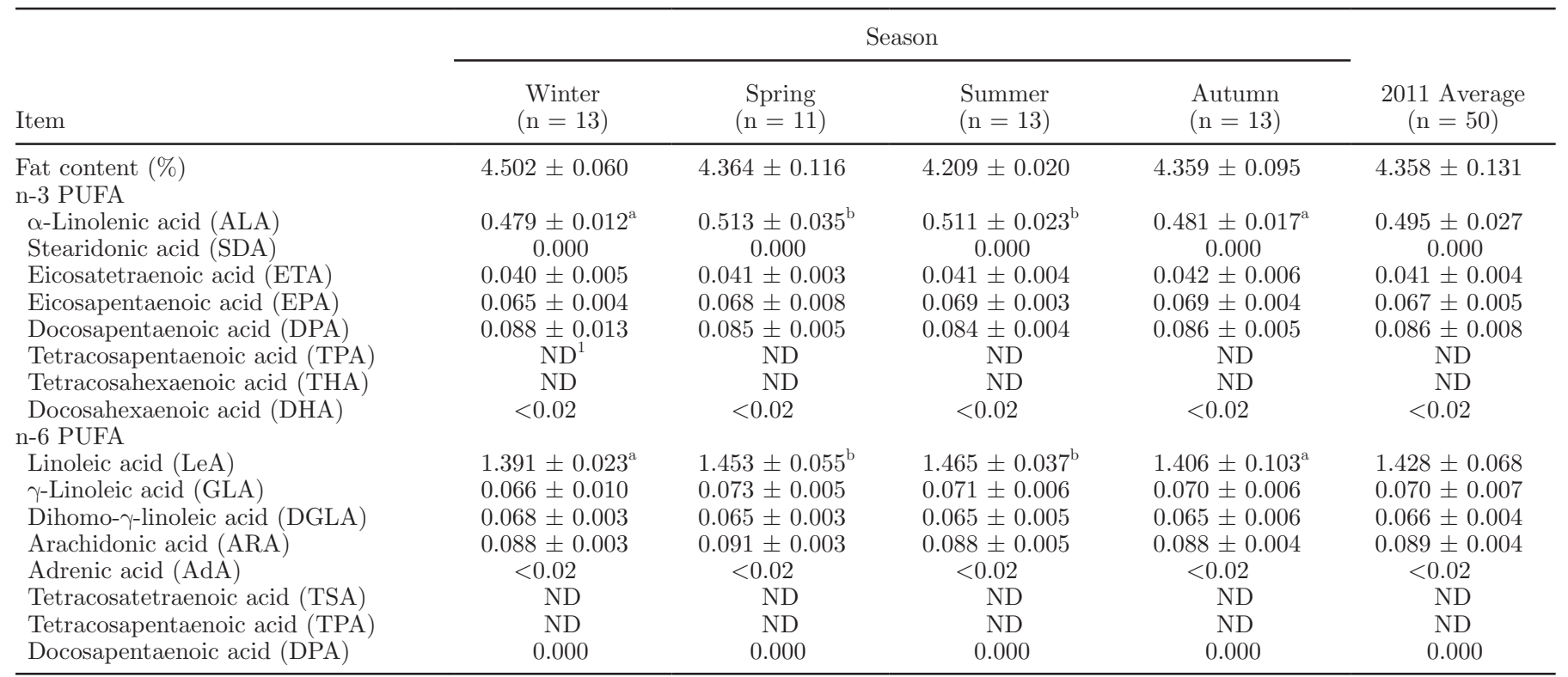

$\overline{\mathrm{a}, \mathrm{b}}$ Means within a row with no common superscript differ significantly $(P<0.01)$ by Duncan's multiple range test.

${ }^{1} \mathrm{ND}=$ not determined.

(Table 2). In line with the results of average Dutch bovine milk (Table 1), the EPA concentration in milk fat with control diets in various experiments reported in the literature is much higher $(0.058 \mathrm{~g} / 100 \mathrm{~g}$ of fat $)$ than that of DHA $(0.018 \mathrm{~g} / 100 \mathrm{~g}$ of fat). However, in control diets of the feeding trials, concentrations higher than $0.04 \mathrm{~g}$ of DHA per $100 \mathrm{~g}$ of fat were obtained. This might be caused by the use of $60-\mathrm{m}$ GC columns instead of the $100-\mathrm{m}$ columns that are nowadays commonly in use. With 60-m columns, co-elution of DHA and DPA n-3 may occur; subsequently, DPA n-3 may be incorrectly assigned as DHA when no standard of the latter has been used for peak identification. Without the results obtained by short GC columns, DHA is absent or present in low concentrations $(<0.04 \mathrm{~g} / 100$ $\mathrm{g}$ of fat) in samples of individual cows of the control diets.

For n-6 PUFA (Table 1) our results for dihomo- $\gamma$ linoleic acid (DGLA) and ARA average concentrations are lower than those reported in the literature (Table 3). Although ALA and LeA concentrations were significantly higher in spring and summer, the average concentrations of ALA- and LeA-derived PUFA were not significantly different between the seasons (Table 1). The low conversion rates of ALA and LeA and the small differences in concentrations between seasons may result in small, undetectable, changes in levels of very long-chain PUFA.

In the first step of the n-3 and n-6 pathways (Figure 1), $\Delta^{6}$-desaturase converts ALA into SDA (18:4n-3) and
LeA into $\gamma$-linoleic acid (GLA; 18:3n-6). In milk fat, SDA was absent or present in low concentrations $(<0.02$ $\mathrm{g} / 100 \mathrm{~g}$ of fat), whereas the average GLA concentration was $0.070 \mathrm{~g} / 100 \mathrm{~g}$ of fat. The low concentrations, or even absence, of SDA is remarkable because the affinity of $\Delta^{6}$-desaturase is higher for $n-3$ than for n- 6 FA (Sprecher, 2002). Desaturation of ALA into SDA is, therefore, expected to occur at a higher rate than the conversion of the n- 6 fatty acid LeA into GLA. Product inhibition of $\Delta^{6}$-desaturase by high levels of LeA (Emken et al., 1994) is unlikely to occur due to the low LeA:ALA ratio (about 3; see Table 1). The low concentrations of SDA may be caused by rapid metabolization of SDA into eicosatetraenoic acid (ETA; 20:4n-3). The rapid conversion of SDA without significant accumulation of ETA has been reported to occur in human blood lipids and mononuclear cells (Miles et al., 2004).

Table 1 shows that the average concentration of ETA was $0.041 \pm 0.004 \mathrm{mg} / 100 \mathrm{~g}$ of fat, which is relatively low compared with average EPA and DPA n-3 (22:5n-3) concentrations of $0.067 \pm 0.005$ and $0.086 \pm 0.008 \mathrm{~g} / 100$ $\mathrm{g}$ of fat, respectively. Desaturation of ETA causes the formation of EPA, which is subsequently elongated to form DPA n-3 (Figure 1). In humans, the main products formed out of ALA are EPA and DPA n-3; the latter may have beneficial biological effects (Kaur et al., 2011) and may also serve as a substrate for metabolic retroconversion to EPA (Russo, 2009). However, the absorption levels of DPA n-3 and the conversion rate to EPA have never been reported. In the generally accepted n-3 


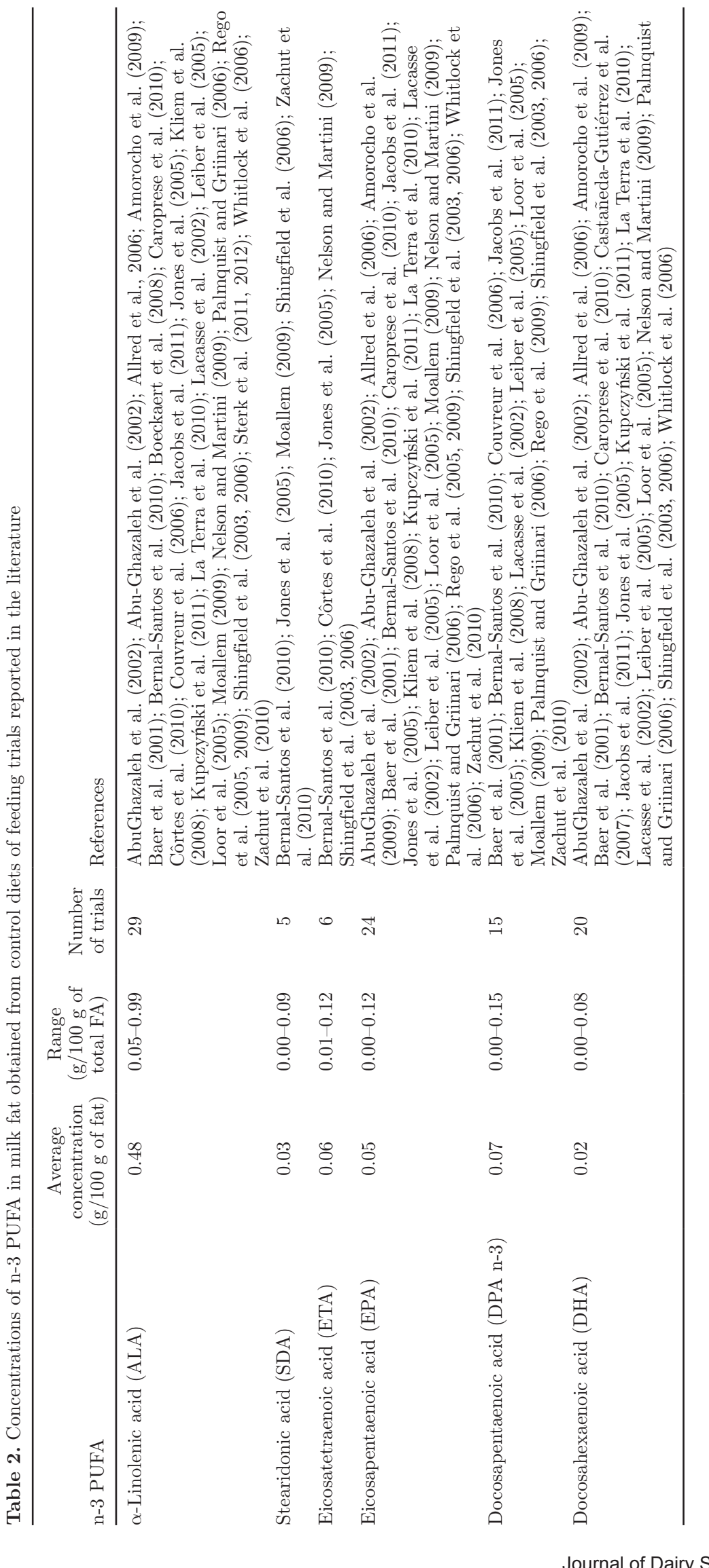




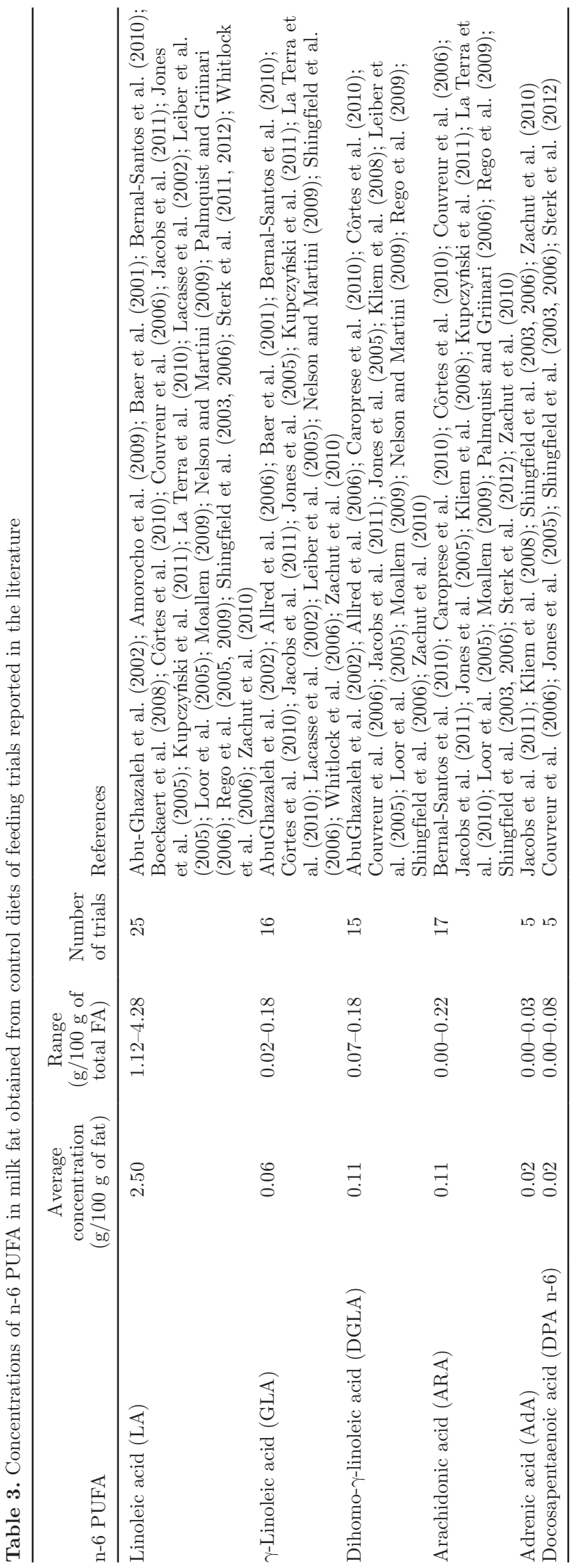

pathway (Figure 1), DPA n-3 is further converted into tetracosapentaenoic acid (TPA; 24:5n-3), tetracosahexaenoic acid (THA; 24:6n-3), and finally DHA.

The conversion of DPA n-3 is the rate-limiting step for the conversion of ALA to DHA (Arterburn et al., 2006). Unfortunately, the intermediates tetracosapentaenoic and tetracosahexaenoic acid could not be determined in our study, which makes it impossible to determine the actual rate-limiting step. Concentrations of DHA were lower than $0.020 \mathrm{~g}$ per $100 \mathrm{~g}$ of fat in all samples, which is in agreement with the low conversion rates from ALA $(<0.1 \%)$ that are frequently reported in the literature (Emken et al., 1994; Goyens et al., 2006; Williams and Burdge, 2006)

Our study confirmed that milk fat is not an important source for DHA intake, but the average EPA concentration of $0.067 \pm 0.005 \mathrm{~g}$ per $100 \mathrm{~g}$ of milk fat (Table 1) implies that milk fat does contribute to human intake of this n-3 FA. Studies on n-3 and n-6 PUFA intake from different food sources report milk fat intakes of 13.7 (Meyer et al., 2003), 15.3 (Sioen et al., 2006), and 26.7 (Astorg et al., 2004) g/d. The intakes of EPA from milk fat are 14.1 (Meyer et al., 2003), 11.6 (Sioen et al., 2006), and $10.7 \%$ (Astorg et al., 2004). Based on these daily milk fat consumptions (Table 4), and the average concentration of $0.067 \mathrm{~g}$ of EPA per $100 \mathrm{~g}$ of fat (Table 1 ), it may be concluded that a substantial part of the EPA intake by humans comes from milk fat. However, the recommend levels of total EPA and DHA cannot be met by increased milk fat consumption because DHA is absent in milk and the intake of milk fat would have to be at an unrealistically high level.

The intakes of DPA n-3, based on the results of this study, are between 23.5 and $34.2 \%$ (Table 4). Therefore, milk is an important source of DPA n-3, together with meat, poultry, and eggs (Astorg et al., 2004). To our knowledge the contribution of different food sources to dietary intake of ETA has never been reported; therefore, ETA was excluded from Table 4. In addition, the contributions of ETA and DPA n-3 to dietary intake must be considered as being unimportant because n-3 fatty acid intake recommendations only consider EPA and DHA. The contribution of ARA to the daily intake was found to be higher than the data from the literature (Table 4).

Milk fat intakes are underestimated because not only dairy products contribute to intake but also milk fat as an ingredient in food products such as chocolate, cookies, puff pastry, and ice cream are sources of milk fat in the human diet. Therefore, the contribution of milk fat to the intake of n-3 and n- 6 PUFA may be higher than the percentages in Table 4 .

In the present analyses, we used the average FA content of Dutch raw bovine milk. Milk FA compo- 
Table 4. Contribution (\%) of milk fat to dietary intake of very long chain n-3 and n-6 PUFA ${ }^{1}$

\begin{tabular}{lccc}
\hline & \multicolumn{3}{c}{ Reference } \\
\cline { 2 - 4 } Item & Meyer et al. (2003) & Sioen et al. (2006) & Astorg et al. (2004) \\
\hline Milk fat intake (g/d) & 13.7 & 15.3 & 26.7 \\
n-3 PUFA & $6.1(11.4)$ & $5.3(6.6)$ & $15.7(24.64)$ \\
--Linolenic acid (ALA) & $14.1(0)$ & $11.6(0)$ & $10.7(0)$ \\
Eicosatetraenoic acid (EPA) & $31.2(0)$ & $34.2(0)$ & $0.0(0)$ \\
Docosapentaenoic acid (DPA n-3) & $0.0(0)$ & $0.0(0)$ & $3.6(5.05)$ \\
Docosahexaenoic acid (DHA) & $1.8(3.18)$ & $1.8(1.9)$ & $10.5(1.06)$ \\
n-6 PUFA & $19.0(0)$ & $19.7(5.9)$ & \\
Linoleic acid (LeA) & $18.8(0.12)$ & & \\
Dihomo- $\gamma$-linoleic acid (DGLA) & &
\end{tabular}

sition is not constant and feeding trials have shown that concentrations of very long chain PUFA may increase significantly due to variation in the diets of dairy cows. For example, the EPA concentration may be increased from 0.06 to $0.10 \mathrm{~g}$ per $100 \mathrm{~g}$ of fat upon supplementation of the dairy cow diet with linseed or linseed oil (Zachut et al., 2010; Sterk et al., 2012); DHA concentration (determined using a 100-m column) may be at least $1 \mathrm{~g} / 100 \mathrm{~g}$ of milk FA when microalgae are included in the cow diet (Boeckaert et al., 2008). In these situations, the contribution of milk fat to daily intake of EPA + DHA may well exceed $50 \%$. Together with the contribution of other food sources mentioned in the literature (Meyer et al., 2003; Astorg et al., 2004; Sioen et al., 2006), consumption of milk fat would cover the recommended value of $450 \mathrm{mg} / \mathrm{d}$ for EPA + DHA intake.

The daily intakes of n-3 and n-6 PUFA (Table 4) are based on data of raw milk and not on dairy products. Limited information is available on the stability of native n-3 and n-6 PUFA during processing of raw milk into dairy products and their stability during storage. Human milk FA composition, including PUFA of both the n- 3 and n- 6 series is not changed after pasteurization, whereas sterilization decreases ARA slightly (Fidler et al., 2001). Fatty acid composition including ALA, LeA, EPA, DPA n-3, and DHA, of pasteurized milk, cream, and butter did not differ from the raw milk used to manufacture these dairy products (Baer et al., 2001).

\section{CONCLUSIONS}

We conclude that EPA is present in milk fat at a constant level throughout the year and it contributes around 10 to $15 \%$ to the daily intake by humans, whereas the contribution of DHA is marginal. Other very long chain n-3 FA that could be quantified in fat from bulk milk are ETA and DPA n-3; however, no recommended daily intakes exist for these n-3 FA. We recommend an update of the current food composition tables after analyses of milk fat composition by the appropriate analytical methods.

\section{ACKNOWLEDGMENTS}

The authors thank Qlip (Zutphen, the Netherlands) for the opportunity to use FA compositions of their samples. We also thank greatly Herman van de Brink (Qlip) and Robert Hovenier (Human Nutrition Department, Wageningen University, Wageningen, the Netherlands) for their work on peak identification and quantification.

\section{REFERENCES}

AbuGhazaleh, A. A., D. J. Schingoethe, A. R. Hippen, K. F. Kalscheur, and L. A. Whitlock. 2002. Fatty acid profiles of milk and rumen digesta from cows fed fish oil, extruded soybeans or their blend. J. Dairy Sci. 85:2266-2276.

Abu-Ghazaleh, A. A., D. J. Schingoethe, A. R. Hippen, and L. A. Whitlock. 2002. Feeding fish meal and extruded soybeans enhances the conjugated linoleic acid (CLA) content of milk. J. Dairy Sci. 85:624-631.

Allred, S. L., T. R. Dhiman, C. P. Brennand, R. C. Khanal, D. J. McMahon, and N. D. Luchini. 2006. Milk and cheese from cows fed calcium salts of palm and fish oil alone or in combination with soybean products. J. Dairy Sci. 89:234-248.

Amorocho, A. K., T. C. Jenkins, and C. R. Staples. 2009. Evaluation of catfish oil as a feedstuff for lactating Holstein cows. J. Dairy Sci. 92:5178-5188.

Anderson, B. M., and D. W. L. Ma. 2009. Are all n-3 polyunsaturated fatty acids created equal? Lipids Health Dis. 8:33.

Arterburn, L. M., E. B. Hall, and H. Oken. 2006. Distribution, interconversion, and dose response of n-3 fatty acids in humans. Am. J. Clin. Nutr. 83:1467S-1476S.

Astorg, P., N. Arnault, S. Czernichow, N. Noisette, P. Galan, and S. Hercberg. 2004. Dietary intakes and food sources of n-6 and n-3 PUFA in French adult men and women. Lipids 39:527-535.

Baer, R. J., J. Ryali, D. J. Schingoethe, K. M. Kasperson, D. C Donovan, A. R. Hippen, and S. T. Franklin. 2001. Composition and properties of milk and butter from cows fed fish oil. J. Dairy Sci. 84:345-353.

Bakewell, L., G. C. Burdge, and P. C. Calder. 2006. Polyunsaturated fatty acid concentrations in young men and women consuming their habitual diets. Br. J. Nutr. 96:93-99. 
Bernal-Santos, G., A. M. O'Donnell, J. L. Vicini, G. F. Hartnell, and D. E. Bauman. 2010. Hot topic: Enhancing omega-3 fatty acids in milk fat of dairy cows by using stearidonic acid-enriched soybean oil from genetically modified soybeans. J. Dairy Sci. 93:32-37.

Bionaz, M. B., and J. J. Loor. 2008. Gene networks driving bovine milk fat synthesis during the lactation cycle. BMC Genet. 9:366

Boeckaert, C., B. Vlaeminck, J. Dijkstra, A. Issa-Zacharia, T. Van Nespen, W. Van Straalen, and V. Fievez. 2008. Effect of dietary starch or micro algae supplementation on rumen fermentation and milk fatty acid composition of dairy cows. J. Dairy Sci. 91:47144727.

Burdge, G. C. 2006. Metabolism of $\alpha$-linolenic acid in humans. Prostaglandins Leukot. Essent. Fatty Acids 75:161-168.

Calder, P. C. 2006. n-3 Polyunsaturated fatty acids, inflammation, and inflammatory diseases. Am. J. Clin. Nutr. 83:1505S-1519S.

Caroprese, M., A. Marzano, R. Marino, G. Gliatta, A. Muscio, and A. Sevi. 2010. Flaxseed supplementation improves fatty acid profile of cow milk. J. Dairy Sci. 93:2580-2588.

Castañeda-Gutiérrez, E., M. J. de Veth, A. L. Lock, D. A. Dwyer, K. D. Murphy, and D. E. Bauman. 2007. Effect of supplementation with calcium salts of fish oil on n-3 fatty acids in milk fat. J. Dairy Sci. 90:4149-4156.

Chilliard, Y., A. Ferlay, and M. Doreau. 2001. Effect of different types of forages, animal fat or marine oils in cow's diet on milk fat secretion and composition, especially conjugated linoleic acid (CLA) and polyunsaturated fatty acids. Livest. Sci. 70:31-48.

Chilliard, Y., F. Glasser, A. Ferlay, L. Bernard, J. Rouel, and M. Doreau. 2007. Diet, rumen biohydrogenation and nutritional quality of cow and goat milk fat. Eur. J. Lipid Sci. Technol. 109:828 855

Côrtes, C., D. C. da Silva-Kazama, R. Kazama, N. Gagnon, C Benchaar, G. T. D. Santos, L. M. Zeoula, and H. V. Petit. 2010 Milk composition, milk fatty acid profile, digestion, and ruminal fermentation in dairy cows fed whole flaxseed and calcium salts of flaxseed oil. J. Dairy Sci. 93:3146-3157.

Couvreur, S., C. Hurtaud, C. Lopez, L. Delaby, and J. L. Peyraud. 2006. The linear relationship between the proportion of fresh grass in the cow diet, milk fatty acid composition, and butter properties. J. Dairy Sci. 89:1956-1969.

Cunnane, S. C., M. A. Ryan, C. R. Nadeau, R. P Bazinet, K. Musa-Veloso, and U. McCloy. 2003. Why is carbon from some polyunsaturates extensively recycled into lipid synthesis? Lipids 38:477-484

Emken, E. A., R. O. Adlof, and R. M. Gulley. 1994. Dietary linoleic acid influences desaturation and acylation of deuterium-labeled linoleic and linolenic acids in young adult males. Biochim. Biophys. Acta 1213:277-288.

Fidler, N., T. U. Sauerwald, H. Demmelmair, and B. Koletzko. 2001 Fat content and fatty acid composition of fresh, pasteurized, or sterilized human milk. Adv. Exp. Med. Biol. 501:485-495.

Goyens, P. L. L., M. E. Spilker, P. L. Zock, M. B. Katan, and R. P. Mensink. 2006. Conversion of $\alpha$-linolenic acid in humans is influenced by the absolute amounts of $\alpha$-linolenic acid and linoleic acid in the diet and not by their ratio. Am. J. Clin. Nutr. 84:44-53.

Hagemeister, H., M. Franzen, C. A. Barth, and D. Precht. 1991. $\alpha$-Linolenic acid transfer into milk fat and its elongation by cows. Fett Wiss. Technologie 93:387-391.

Heck, J. M. L., H. J. F. van Valenberg, J. Dijkstra, and A. C. M. van Hooijdonk. 2009. Seasonal variation in the Dutch bovine raw milk composition. J. Dairy Sci. 92:4745-4755.

ISO (International Organization for Standardization). 2002a. Milk Fat-Preparation of fatty acid methyl esters. ISO 15884:2002. ISO, Geneva, Switzerland.

ISO (International Organization for Standardization). 2002b. Milk fat-Determination of the fatty acid composition by gas-liquid chromatography. ISO 15885:2002. ISO, Geneva, Switzerland.

Jacobs, A. A. A., J. van Baal, M. A. Smits, H. Z. H. Taweel, W. H. Hendriks, A. M. van Vuuren, and J. Dijkstra. 2011. Effects of feeding rapeseed oil, soybean oil, or linseed oil on stearoyl-CoA desaturase expression in the mammary gland of dairy cows. J. Dairy Sci. 94:874-887.
Jensen, R. G. 2002. The composition of bovine milk lipids: January 1995 to December 2000. J. Dairy Sci. 85:295-350.

Jones, E. L., K. J. Shingfield, C. Kohen, A. K. Jones, B. Lupoli, A. S. Grandison, D. E. Beever, C. M. Williams, P. C. Calder, and P. Yaqoob. 2005. Chemical, physical, and sensory properties of dairy products enriched with conjugated linoleic acid. J. Dairy Sci. 88:2923-2937.

Kaur, G., D. Cameron-Smith, M. Garg, and A. J. Sinclair. 2011. Docosapentaenoic acid (22:5n-3): A review of its biological effects. Prog. Lipid Res. 50:28-34.

Kliem, K. E., R. Morgan, D. J. Humphries, K. J. Shingfield, and D. I. Givens. 2008. Effect of replacing grass silage with maize silage in the diet on bovine milk fatty acid composition. Animal 2:1850-1858.

Kris-Etherton, P. M., J. A. Grieger, and T. D. Etherton. 2009. Dietary reference intakes for DHA and EPA. Prostaglandins Leukot. Essent. Fatty Acids 81:99-104

Kupczyński, R., M. Szołtysik, W. Janeczek, J. Chrzanowska, S. Kinal, and B. Króliczewska. 2011. Effect of dietary fish oil on milk yield fatty acids content and serum metabolic profile in dairy cows. J. Anim. Physiol. Anim. Nutr. (Berl.) 95:512-522.

La Terra, S., V. M. Marino, M. Manenti, G. Licitra, and S. Carpino. 2010. Increasing pasture intakes enhances polyunsaturated fatty acids and lipophilic antioxidants in plasma and milk of dairy cows fed total mix ration. Dairy Sci. Technol. 90:687-698.

Lacasse, P., J. J. Kennelly, L. Delbecchi, and C. E. Ahnadi. 2002. Addition of protected and unprotected fish oil to diets for dairy cows. I. Effects on the yield, composition and taste of milk. J. Dairy Res. 69:511-520.

Leiber, F., M. Kreuzer, D. Nigg, H. R. Wettstein, and M. R. Scheeder. 2005. A study on the causes for the elevated n-3 fatty acids in cows' milk of alpine origin. Lipids 40:191-202.

Lock, A. L., and D. E. Bauman. 2004. Modifying milk fat composition of dairy cows to enhance fatty acids beneficial to human health. Lipids 39:1197-1206.

Loor, J. J., M. Doreau, J. M. Chardigny, A. Ollier, J. L. Sebedio, and Y. Chilliard. 2005. Effects of ruminal or duodenal supply of fish oil on milk fat secretion and profiles of trans-fatty acids and conjugated linoleic acid isomers in dairy cows fed maize silage. Anim. Feed Sci. Technol. 119:227-246.

Meyer, B. J., N. J. Mann, J. L. Lewis, G. C. Milligan, A. J. Sinclair, and P. R. Howe. 2003. Dietary intakes and food sources of omega-6 and omega-3 polyunsaturated fatty acids. Lipids 38:391-398.

Miles, E. A., T. Banerjee, and P. C. Calder. 2004. The influence of different combinations of $\gamma$-linolenic, stearidonic and eicosapentaenoic acids on the fatty acid composition of blood lipids and mononuclear cells in human volunteers. Prostaglandins Leukot. Essent. Fatty Acids 70:529-538.

Moallem, U. 2009. The effects of extruded flaxseed supplementation to high-yielding dairy cows on milk production and milk fatty acid composition. Anim. Feed Sci. Technol. 152:232-242.

Nelson, K. A. S., and S. Martini. 2009. Increasing omega fatty acid content in cow's milk through diet manipulation: Effect on milk flavor. J. Dairy Sci. 92:1378-1386.

O'Donnell, A. M., K. P. Spatny, J. L. Vicini, and D. E. Bauman. 2010 Survey of the fatty acid composition of retail milk differing in label claims based on production management practices. J. Dairy Sci. 93:1918-1925.

Palmquist, D. L., and J. M. Griinari. 2006. Milk fatty acid composition in response to reciprocal combinations of sunflower and fish oils in the diet. Anim. Feed Sci. Technol. 131:358-369.

Ratnayake, W. M. N., and C. Galli. 2009. Fat and fatty acid terminology, methods of analysis and fat digestion and metabolism: A background review paper. Ann. Nutr. Metab. 55:8-43.

Rego, O. A., S. P. Alves, L. M. S. Antunes, H. J. D. Rosa, C. F. M. Alfaia, J. A. M. Prates, A. R. J. Cabrita, A. J. M. Fonseca, and R. J. B. Bessa. 2009. Rumen biohydrogenation-derived fatty acids in milk fat from grazing dairy cows supplemented with rapeseed, sunflower, or linseed oils. J. Dairy Sci. 92:4530-4540.

Rego, O. A. H. J. D. Rosa, P. Portugal, R. Cordeiro, A. E. S. Borba, C. M. Vouzela, and R. J. B. Bessa. 2005. Influence of dietary fish 
oil on conjugated linoleic acid, omega-3 and other fatty acids in milk fat from grazing dairy cows. Livest. Prod. Sci. 95:27-33.

Russo, G. L. 2009. Dietary n-6 and n-3 polyunsaturated fatty acids: From biochemistry to clinical implications in cardiovascular prevention. Biochem. Pharmacol. 77:937-946.

Schmitz, G., and J. Ecker. 2008. The opposing effects of n-3 and n-6 fatty acids. Prog. Lipid Res. 47:147-155.

Shingfield, K. J., S. Ahvenjärvi, V. Toivonen, A. Ärölä, K. V. V. Nurmela, P. Huhtanen, and J. M. Griinari. 2003. Effect of dietary fish oil on biohydrogenation of fatty acids and milk fatty acid content in cows. Anim. Sci. 77:165-179.

Shingfield, K. J., C. K. Reynolds, G. Hervás, J. M. Griinari, A. S. Grandison, and D. E. Beever. 2006. Examination of the persistency of milk fatty acid composition responses to fish oil and sunflower oil in the diet of dairy cows. J. Dairy Sci. 89:714-732.

Simopoulos, A. P. 2008. The importance of the omega-6/omega-3 fatty acid ratio in cardiovascular disease and other chronic diseases. Exp. Biol. Med. (Maywood) 233:674-688.

Sioen, I. A., I. Pynaert, C. Matthys, G. De Backer, J. Van Camp, and S. De Henauw. 2006. Dietary intakes and food sources of fatty acids for Belgian women, focused on n- 6 and n- 3 polyunsaturated fatty acids. Lipids 41:415-422.

Sprecher, H. 2000. Metabolism of highly unsaturated n-3 and n-6 fatty acids. Biochim. Biophys. Acta 1486:219-231.

Sprecher, H. 2002. The roles of anabolic and catabolic reactions in the synthesis and recycling of polyunsaturated fatty acids. Prostaglandins Leukot. Essent. Fatty Acids 67:79-83.

Sterk, A., B. E. O. Johansson, H. Z. H. Taweel, M. Murphy, A. M. van Vuuren, W. H. Hendriks, and J. Dijkstra. 2011. Effects of forage type, forage to concentrate ratio, and crushed linseed supplemen- tation on milk fatty acid profile in lactating dairy cows. J. Dairy Sci. 94:6078-6091.

Sterk, A., B. Vlaeminck, A. M. van Vuuren, W. H. Hendriks, and J. Dijkstra. 2012. Effects of feeding different linseed sources on omasal fatty acid flows and fatty acid profiles of plasma and milk fat in lactating dairy cows. J. Dairy Sci. 95:3149-3165.

Walstra, P., J. T. M. Wouters, and T. J. Geurts. 2006. Dairy Science and Technology. 2nd ed. Taylor \& Francis, CRC Press, London, UK.

Welch, A. A., S. Shakya-Shrestha, M. A. H. Lentjes, N. J. Wareham, and K.-T. Khaw. 2010. Dietary intake and status of n-3 polyunsaturated fatty acids in a population of fish-eating and non-fisheating meat-eaters, vegetarians, and vegans and the precursorproduct ratio of $\alpha$-linolenic acid to long-chain n-3 polyunsaturated fatty acids: Results from the EPIC-Norfolk cohort. Am. J. Clin. Nutr. 92:1040-1051.

Whitlock, L. A., D. J. Schingoethe, A. A. AbuGhazaleh, A. R. Hippen, and K. F. Kalscheur. 2006. Milk production and composition from cows fed small amounts of fish oil with extruded soybeans. J. Dairy Sci. 89:3972-3980.

Williams, C. M., and G. Burdge. 2006. Long-chain n-3 PUFA: Plant v. marine sources. Proc. Nutr. Soc. 65:42-50.

Woods, V. B., and A. M. Fearon. 2009. Dietary sources of unsaturated fatty acids for animals and their transfer into meat, milk and eggs: A review. Livest. Sci. 126:1-20.

Zachut, M., A. Arieli, H. Lehrer, L. Livshitz, S. Yakoby, and U. Moallem. 2010. Effects of increased supplementation of n-3 fatty acids to transition dairy cows on performance and fatty acid profile in plasma, adipose tissue, and milk fat. J. Dairy Sci. 93:5877-5889. 